\title{
Desenvolvimento e eficácia anti-inflamatória não clínica de uma formulação anti-acne
}

\author{
Development and nonclinical anti-inflammatory effectiveness of an anti-acne formulation \\ F. G. S. Lima ${ }^{1 *}$; J. M. A. Melo Júnior ${ }^{1}$; F. N. Costa ${ }^{1}$; A. R. Campos ${ }^{1}$ \\ ${ }^{1}$ Núcleo de Biologia Experimental,Universidade de Fortaleza 60811-905, Fortaleza-Ceará, Brasil \\ *fgilvans@hotmail.com
}

(Recebido em 12 de abril de 2016; aceito em 08 de dezembro de 2016)

\begin{abstract}
O processo inflamatório participa de todos os estágios do desenvolvimento da lesão acnéica. As plantas medicinais produzem compostos bioativos que lhes conferem ações terapêuticas, podendo ser utilizadas no tratamento de afecções da pele. Este trabalho teve como objetivo elaborar e testar a eficácia antiinflamatória não clínica de uma formulação (gel-creme) contendo extratos glicólicos de Aloe vera, Ginkgo biloba L., Panax ginseng, Matricaria recutita e mel de abelha. Foram realizados estudos preliminares de estabilidade. As amostras foram analisadas com respeito às propriedades organolépticas, $\mathrm{pH}$, centrifugação e gelo-degelo, durante 8 semanas. Foi realizada a avaliação do efeito anti-inflamatório tópico da formulação em modelo experimental de inflamação cutânea utilizando camundongos Swiss e C57BL/6J. Os animais receberam aplicações tópicas de óleo de Croton durante 9 dias e, a partir do $5^{\circ}$ dia, foram tratados com o gel-creme teste ou gel-creme base (controle), duas vezes ao dia. A formulação apresentou boa estabilidade físico-química e inibiu o edema de orelha, tendo seu efeito anti-inflamatório mais evidente nos camundongos C57BL/6J. Este resultado sugere que a formulação é eficaz como agente anti-inflamatório tópico no processo inflamatório crônico, o que justificaria o seu uso no tratamento da acne.

Palavras-chave: Gel-creme, Compostos biativos, Óleo de Croton.
\end{abstract}

The inflammatory process appears to participate in all stages of the development of acne lesion. Medicinal plants produce bioactive compounds that impart numerous therapeutic actions, and they can be used for the treatment of skin diseases. This work aimed to develop and to test the non-clinical anti-inflammatory effect of a formulation (cream-gel) containing glycolic extracts of Aloe Vera, Ginkgo biloba, Panax ginseng, Matricaria recutita and honey bee. Preliminary stability studies were carried out. The samples were analyzed with respect to organoleptic properties, $\mathrm{pH}$ variation, centrifugation and ice-melt, for 8 weeks. The anti-inflammatory effect of the cream-gel was evaluated using experimental model of cutaneous inflammation in Swiss and C57BL/6J mice. Animals received topical application of Croton oil for 9 days and, from day 5, they were treated with the cream-gel test or cream-gel base (control), twice daily. The formulation presented good physical and chemical stability and it inhibited the ear edema and the response was more evident in the $\mathrm{C} 57 \mathrm{BL} / 6 \mathrm{~J}$ strain. This result suggests that the formulation is effective as topical anti-inflammatory agent in chronic inflammatory process, justifying its use in the treatment of acne.

Keywords: Cream-gel, Bioactive compounds, Croton oil.

\section{INTRODUÇÃO}

Acne vulgaris, conhecida como acne, é uma doença inflamatória crônica da unidade pilossebácea [1]. Características da acne incluem seborreia (excesso de produção de óleo), lesões não-inflamatórias (comedões abertos e fechados), lesões inflamatórias (pápulas e pústulas), vários níveis de cicatrizes e, em casos graves, nódulos e cistos [1]. Essa patologia afeta aproximadamente $80 \%$ das pessoas em algum momento de suas vidas, embora, seja mais comum em adolescentes com idades de 15 e 17 anos [2].

Diversos medicamentos são utilizados como agentes combatentes à acne, porém, causam inúmeros efeitos adversos: ácido salicílico pode causar irritação, vermelhidão e descamação da pele [3,4]; o uso dos retinóides tópicos está associado ao surgimento de eritema, descamação e hipersensibilidade na pele [5] o peróxido de benzoíla leva a pele seca, descamação e eritema [5]. 
Os cosméticos também podem ser utilizados como adjuvantes terapêuticos no tratamento da acne vulgar, geralmente são usados produtos que atuam na limpeza e controle da oleosidade e que diminuam a irritação provocada pelos medicamentos de uso tópicos ou sistêmicos [6].

Outra classe de produtos que podem atuar como adjuvantes terapêuticos são os cosmecêuticos, também chamados de dermocosméticos, estes contêm compostos bioativos, e são empregados para os mais diversos fins, como: prevenindo e atenuando rugas, eliminando manchas de pele e minimizando cicatrizes [7]. Os cosmecêuticos são úteis como coadjuvantes nos tratamentos clínicos medicamentosos, em procedimentos que melhorem a aparência da pele, e na manutenção de resultados, uma vez que veiculam substâncias antioxidantes, anti-inflamatórias e vitaminas com ação terapêutica sobre a pele [7].

O estudo dos vegetais e a aplicação dos seus constituintes na forma de extratos ou substâncias ativas, surgido do oriente e difundindo-se para o mundo, tem cada vez mais espaço na indústria de cosméticos moderna atual. Na literatura, encontra-se um vasto número de plantas com propriedades dermatológicas reconhecidas, que podem ser utilizadas nas composições de cosmecêuticos. Dentre as quais, destacamos algumas plantas com propriedades anti-inflamatórias e dermatológicas comprovadas, e também o mel de abelha [8].

Aloe vera possui várias substâncias com propriedades bioativas e dermatológicas, como as vitaminas $\mathrm{A}, \mathrm{C}$ e E, além do polissacarídeo acemannan, que possui alta atividade imunomoduladora, cicatrizante, antibacteriana e antifúngica [9]. As mucilagens do Aloe vera também são responsáveis pelas propriedades hidratante, bactericida, antiviral e protetora da radiação UV [10].

Matricaria recutita possui óleo essencial rico em $\alpha$-bisabolol, um álcool sesquiterpênico monocíclico, que é reconhecido por suas propriedades anti-inflamatórias, e bactericida, além disso, também possui camazulenos e flavonóides que contribuem efetivamente para o efeito antiinflamatório [11,12].

A presença de flavonóides e biflavonóides no Ginkgo biloba confere a esta planta atividades anti-inflamatória, anti-irritante e bactericida, além de uma intensa atividade antioxidante e promoção da síntese de colágeno [13,14].

Panax ginseng melhora a circulação sanguínea da pele, reduz a queratinização, deixando a pele macia e hidratada. Os ginsenosídeos possuem ação clareadora e antioxidante, combatendo o envelhecimento, aliviando e prevenindo as rugas [11].

O mel de abelha ativa a reparação tecidual [15] e vem sendo utilizado na composição de medicamentos para o tratamento de diversos tipos de ferimentos, queimaduras de primeiro e segundo grau, úlceras, pé diabético, feridas infectadas, atuando como antimicrobiano natural e cicatrizante [16].

O presente trabalho buscou desenvolver e avaliar a eficácia anti-inflamatória não clínica de uma formulação anti-acne, como uma nova opção para auxiliar no tratamento da inflamação causada pela acne vulgar.

\section{MATERIAL E MÉTODOS}

\subsection{INSUMOS}

Natrosol 250; EDTA; propilenoglicol; metilparabeno; álcool cetoestearílico etoxildado; álcool cetoestearílico; ciclometicone DC 245; silicone 9040; água deionizada; Extrato glicólico 5\% de: Aloe vera; Ginkgo biloba L.; Panax ginseng; Matricaria recutita e mel de abelha.

\subsection{MANIPULAÇÃO DO GEL-CREME BASE}

O gel-creme foi manipulado no Laboratório de Desenvolvimento Farmacotécnico na Universidade de Fortaleza (UNIFOR), onde os componentes atenderam as legislações vigentes: $\mathrm{RDC} \mathrm{N}^{\circ}$ 04, de 30/01/14 [17], RDC 03 de 18/01/12 [18] e RDC 29 de 01/06/2012 [19].

Para a preparação do gel-creme base, diluiu-se o Natrosol 250 com água q.s.p. $100 \%$, sob leve aquecimento $\left(25^{\circ} \mathrm{C}\right)$ até a formação do gel. Adicionou-se o EDTA previamente diluído, 
homogeneizando a mistura constantemente aquecido até $45^{\circ} \mathrm{C}$. Em seguida o propilenoglicol e o metilparabeno foram solubilizados em banho-maria e adicionados ao gel inicial. Na segunda fase do processo, o álcool cetoestearílico etoxilado e o álcool cetoestearílico foram fundidos em banho-maria a temperatura de $80{ }^{\circ} \mathrm{C}$, e também adicionados ao gel, homogeneizando por $8-10$ min para o choque e a formação do creme, sendo submetido a alta rotação por $10 \mathrm{~s}$. $\mathrm{O}$ ciclometicone DC 245 e o silicone 9040 foram misturados previamente e adicionados ao gelcreme quando este atingiu a temperatura de $45^{\circ} \mathrm{C}$ e depois homogeneizado por 10 min [20]. Deixou-se esfriar o gel-creme a temperatura de $22^{\circ} \mathrm{C}$ para adicionar os extratos.

\subsection{TESTES PRELIMINARES DE ESTABILIDADE}

A estabilidade da formulação foi avaliada por testes preliminares constituídos por determinação da aparência, estresse térmico, centrifugação e determinação do $\mathrm{pH}$. Para isso, as amostras foram separadas em quatro grupos, sendo o primeiro grupo colocado em estufa a $45^{\circ} \mathrm{C}$, o segundo em geladeira a $5{ }^{\circ} \mathrm{C}$ e o terceiro mantido em temperatura ambiente entre 23 e $25^{\circ} \mathrm{C}$. Estas amostras foram analisadas, com respeito à aparência, alteração de cor, odor e variação de $\mathrm{pH}$, de 7 em 7 dias, durante 60 dias. A quarta amostra do produto foi submetida ao ciclo gelo degelo, todos os testes foram realizados seguindo os procedimentos descritos na literatura [21,22].

\subsection{CENTRIFUGAÇÃO}

O gel-creme foi centrifugado (LS3 PLUS/CELM) a $3000 \mathrm{rpm}, 25^{\circ} \mathrm{C}$ por $30 \mathrm{~min}$ após $24 \mathrm{~h}$ da sua produção, com o objetivo de verificar uma possível instabilidade inicial da formulação [21].

\subsection{DETERMINAÇÃO DAS CARACTERÍSTICAS ORGANOLÉPTICAS}

As características organolépticas avaliadas foram: aspecto, cor e odor. Para esta avaliação, foi adicionada uma alíquota da amostra em vidro relógio, e em seguida analisada sobre um fundo branco em comparação a um produto padrão. O aspecto e a cor foram avaliados visualmente e o odor diretamente através do olfato [21].

\subsection{DETERMINAÇÃO DO PH}

$\mathrm{O}$ pH da formulação foi determinado utilizando-se uma solução a $10 \%(\mathrm{~m} / \mathrm{v})$, obtida pela dispersão de $2 \mathrm{~g}$ da formulação em água destilada com o auxílio do agitador magnético na velocidade 4 por 15 minutos, sendo as determinações realizadas com medidor de $\mathrm{pH}$ previamente calibrado com soluções-tampão pH 4 e pH 7 [21].

\subsection{CICLO GELO-DEGELO}

O produto foi colocado em estufa a $40{ }^{\circ} \mathrm{C}$ por 7 dias e, seguindo-se pela manutenção em geladeira pelo mesmo tempo. Após esse período, foi levado novamente à estufa onde permaneceu por mais 7 dias, completando-se um ciclo de 21 dias. Decorrido esse tempo, a amostra foi analisada, com respeito à aparência, alteração de cor, odor e variação de pH [21].

\subsection{ANIMAIS}

Foram utilizados camundongos ( 20 a $30 \mathrm{~g}$; $\mathrm{n}=6$ /grupo) machos e fêmeas das linhagens Swiss e C57BL/6J oriundos do Núcleo de Biologia Experimental (NUBEX) da Universidade de Fortaleza. Os animais foram acondicionados em gaiolas apropriadas e mantidos sob temperatura média de $22{ }^{\circ} \mathrm{C}$ em ciclos claro/escuro de $12 / 12 \mathrm{~h}$, recebendo ração padrão e água ad libitum. Todos os protocolos seguiram as normas internacionais de cuidados com animais de laboratório. O projeto 
foi aprovado pela Comissão de Ética no Uso de Animais (CEUA/UNIFOR, parecer $\mathrm{N}^{\circ}$ 007/2015).

\subsection{EDEMA DE ORELHA INDUZIDO PELA APLICAÇÃO MÚLTIPLA DO ÓLEO DE CRÓTON}

O processo inflamatório crônico foi induzido pela aplicação do óleo de Croton $(0,4 \mathrm{mg} /$ orelha em $20 \mu \mathrm{L}$ de acetona) em dias alternados durante 9 dias. Após o quinto dia do experimento, o gelcreme teste foi aplicado ( $1 \mathrm{mg} /$ orelha), por via tópica, durante 4 dias (2 vezes ao dia), sendo o edema avaliado diariamente [23]. Os animais foram distribuídos em dois grupos: grupo controle (gel-creme base) e o grupo teste (gel-creme teste). O edema de orelha foi expresso como o aumento da espessura da orelha dos camundongos $(\mu \mathrm{m})$.

\subsection{ANÁLISE ESTATÍSTICA}

Os resultados do pH e da avaliação da atividade anti-inflamatória estão expressos em média \pm erro padrão da média (E.P.M). A comparação entre as médias foi realizada utilizando-se teste t de Student. Foram consideradas diferenças significativas valores de $\mathrm{p}<0,05$.

\section{RESULTADOS E DISCUSSÃO}

O produto final manipulado apresentou-se como um gel-creme com uma textura delicada de toque leve e agradável, com ótima penetração através da pele. Os resultados dos testes realizados para avaliação da estabilidade físico-química do gel-creme estão descritos abaixo, seguido pelo resultado da avaliação da eficácia anti-inflamatória não clínica.

\subsection{CARACTERÍSTICAS ORGANOLÉPTICAS}

Os ensaios organolépticos avaliam as características, perceptíveis pelos órgãos do sentido, deste modo, fornecendo parâmetros para avaliar produtos cosméticos através de análises comparativas com a finalidade de identificar incompatibilidades intrínsecas e extrínsecas da formulação, que podem ser observadas pelo surgimento de separação de fases, precipitação, cristalização formação de gretas, entre outras [21]. Durante todo o período do estudo, não foram observadas alterações no aspecto, cor e odor nas amostras submetidas a temperatura ambiente, geladeira ou estufa. Podendo-se concluir que não ocorreram reações de oxidação ou redução que comprometeriam a estabilidade do produto.

\subsection{TESTE DE CENTRIFUGAÇÃO}

Normalmente a gravidade exerce sua força nos produtos, movendo as partículas no interior dos mesmos. No ensaio de centrifugação, a força da gravidade é aumentada provocando um estresse na amostra, acelerando a mobilidade das partículas que podem causar precipitação, separação de fases e coalescência, antecipando possíveis instabilidades no produto [21]. Após este teste, a formulação não apresentou alteração, em relação ao seu aspecto original, mantendo sua cor e textura, sem separação de fases ou formação de precipitados.

\subsection{CICLO GELO-DEGELO}

O ciclo gelo-degelo é descrito como um procedimento utilizado para avaliar a estabilidade de forma a antecipar os processos de separação de fases da emulsão sob condições normais de estocagem. Com esse método é possível verificar alterações significativas nas características 
físicas e organolépticas das formulações [21]. Os resultados deste ensaio encontram-se apresentados na Tabela 1.

Ao final do experimento, a formulação testada não sofreu alterações pelas condições de estresse térmico. Não foi observada alteração macroscópica na formulação.

Tabela 1: Estabilidade preliminar da formulação após um ciclo alternado de temperatura, durante 21 dias.
Formulação
Microscopia
Cor
Odor
pH

\begin{tabular}{lllll}
\hline Valores iniciais & Sem alteração & Normal, satisfatório & Normal, satisfatório & 4,85 \\
Valores finais & Sem alteração & Normal, satisfatório & Normal, satisfatório & 4,82 \\
\hline
\end{tabular}

\subsection{DETERMINAÇÃO DO pH}

O logaritmo negativo da concentração molar de íons de hidrogênio $(\mathrm{pH})$ representa convencionalmente a acidez ou a alcalinidade de uma solução. A determinação do $\mathrm{pH}$ em um produto avalia aspectos relacionados a estabilidade dos ingredientes da formulação, eficácia e segurança do produto [21]. Os resultados dos testes realizados para determinar o pH da formulação estão descritos abaixo.

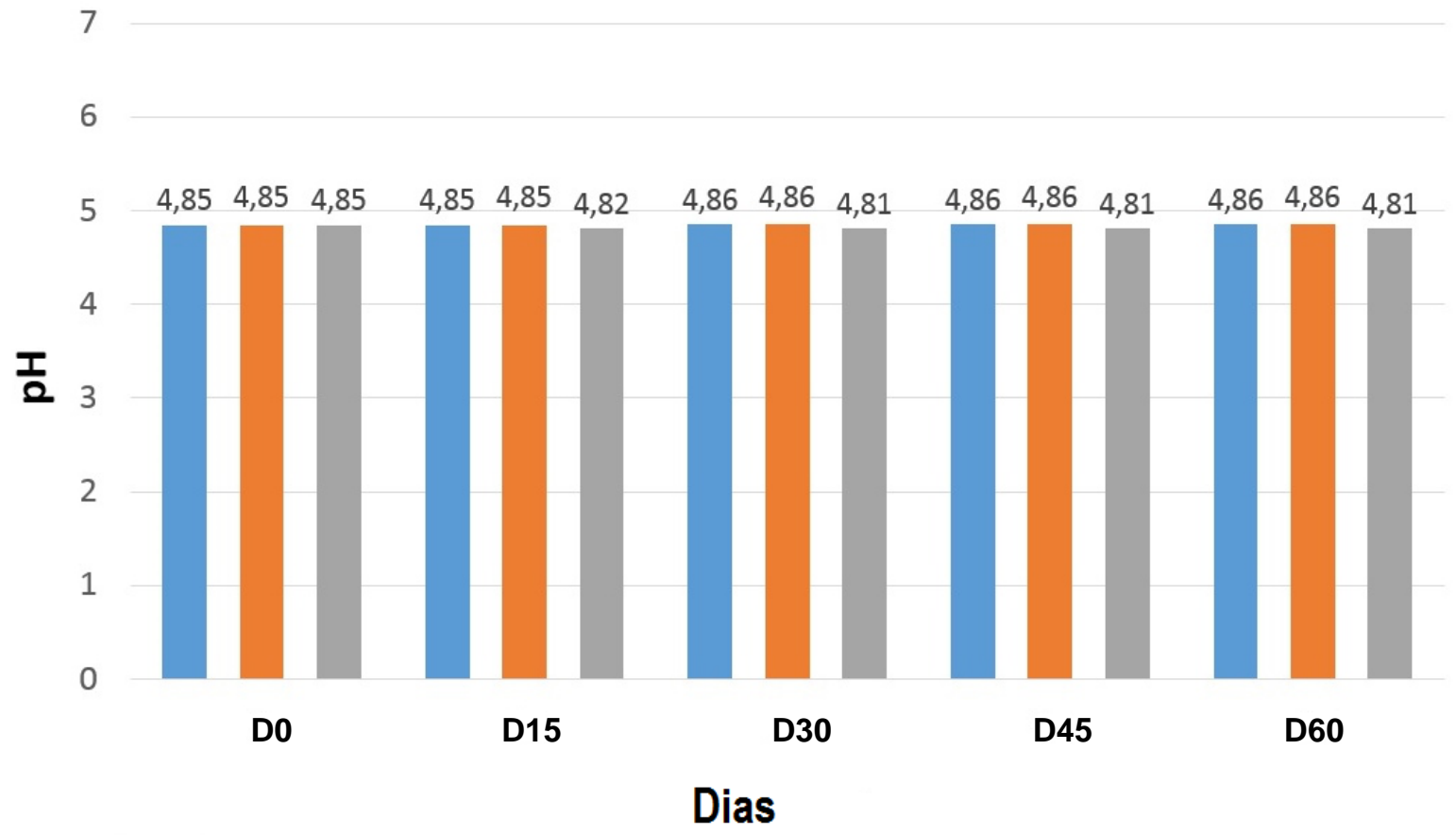

\section{$\mathrm{TA} \square \mathrm{GE} 5^{\circ}-\mathrm{ES} 45^{\circ}$}

Figura 1: $\mathrm{pH}$ da formulação num período de 60 dias em temperatura ambiente (TA), geladeira $5^{\circ} \mathrm{C}(\mathrm{GE}) \mathrm{e}$ estufa $45^{\circ} \mathrm{C}(\mathrm{ES})$.

Analisando os dados dispostos na Figura 1, foi possível observar que não houve alteração do $\mathrm{pH}$ da formulação armazenada em diferentes condições durante 60 dias. O gráfico também demonstra a princípio, a estabilidade e segurança da formulação estudada apresentando valores dentro da faixa compatível com a pele que varia de $\mathrm{pH}$ 4,2 a 5,6 [24]. 


\subsection{AVALIAÇÃO DO EFEITO ANTI-INFLAMATÓRIO}

O óleo de Croton, agente flogístico bastante utilizado em modelos de inflamação cutânea, apresenta ação tópica e induz uma inflamação local persistente, semelhante a algumas dermatites observadas em seres humanos. Seu efeito inflamatório está relacionado à ativação da proteínaquinase $\mathrm{C}$, aumentando a permeabilidade vascular, induzindo a síntese de metabólicos do ácido araquidônico, promovendo a expressão da cicloxigenase-2 (COX-2), interleucina $1 \beta$ (IL-1 $\beta$ ) e fator de necrose tumoral alfa (TNF- $\alpha$ ); esses fatores promoverão o surgimento de edema infiltração celular, com predomínio de células mononucleares, e hiperproliferação celular na epiderme [25, 26, 27].

Gel

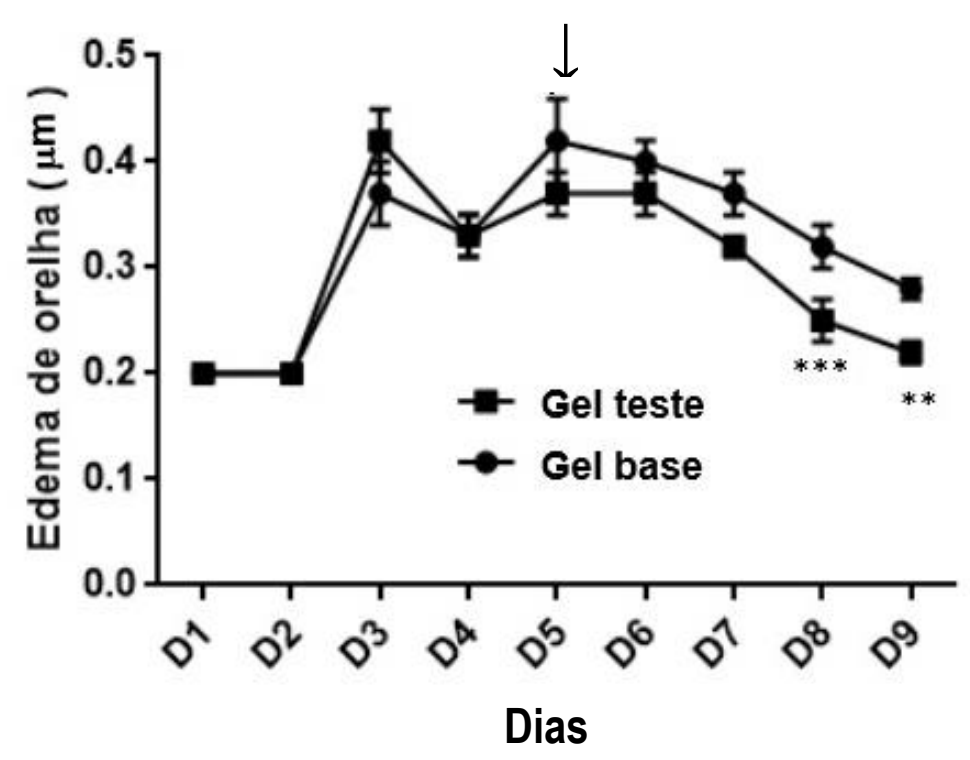

Figura 2: Efeito anti-inflamatório do gel no teste de inflamação cutânea induzida por aplicação múltipla do óleo de Croton em camundongos Swiss. Os valores estão expressos como média \pm EPM. *p<0,05 (Gelteste $x$ Gel-base), **p<0,01 (D9 $x$ D3) $e^{* * * p<0,001 ~(D 8 x ~ D 3) . ~}$

Gel

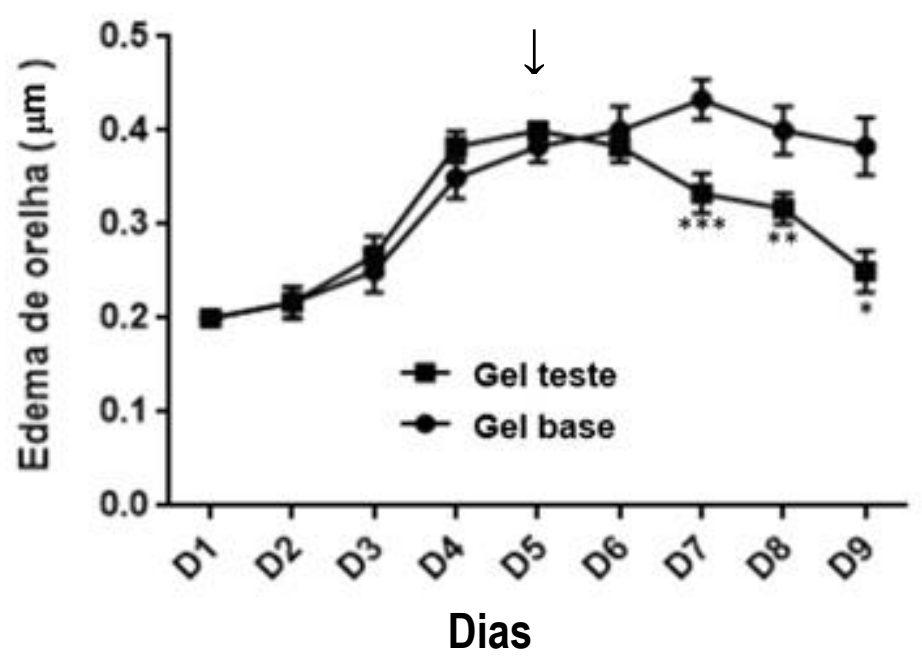

Figura 3: Efeito anti-inflamatório do gel no teste de inflamação cutânea induzida por aplicação múltipla do óleo de Croton em camundongos C57BL/6J. Os valores estão expressos como média \pm EPM. Gel-teste $x$ Gel-base: ***p<0,05(D7); **p<0,05(D8); *p<0,05. (D9) representam o nível de significância em relação ao controle. 
Observa-se que após o estabelecimento do processo inflamatório crônico por aplicação múltipla do óleo de Croton, ocorreu uma reversão significativa do quadro inflamatório a partir do dia $8^{\circ}$. dia nos camundongos Swiss tratados com o gel-teste (Figura 2) e partir do $7^{\circ}$. dia nos camundongos C57BL/6J (Figura 3). Além disso, o edema foi mais proeminente nos camundongos C57BL/6J, sugerindo que esta linhagem é mais adequada para o modelo em estudo.

Davis et al. (1987) [28] demonstraram que a aplicação tópica de Aloe vera diminui o edema de orelha induzido por óleo de Croton e que não atuaria como um esteróide. O efeito antiinflamatório pode estar relacionado ao bloqueio da síntese de prostaglandinas e tromboxano, além de ação antioxidante da vitamina E presente na planta [29]. Recentemente, foi sugerido que o gel de Aloe vera pode ser uma alternativa segura eficaz aos anti-histamínicos e corticoesteróides para o tratamento da dermatite atópica crônica [30].

Ginkgetina, bioflavonóide encontrado no Ginkgo biloba, inibe a fosfolipase A2 e suprime a expressão gênica de $\mathrm{COX}-2$ e óxido nítrico sintase induzível. A aplicação tópica deste biflavonóide diminuiu o edema de orelha, produção de PGE2 (prostaglandina E2), a hiperplasia epidérmica e a expressão gênica de IL-1 $\beta$ [31]. Também foi demonstrando que polissacarídeos do Ginkgo biloba interferem com interação entre moléculas de adesão e seus ligantes levando a inibição do processo inflamatório [32].

Os ginsenosídeos, principais constituintes do Panax ginseng, têm sido utilizados para o tratamento de irritações da pele e este efeito pode ocorrer devido a inibição da produção de IL-17 e de espécies reativas de oxigênio [33], além de TNF- $\alpha$ e IL-1 $\beta$ [34] e da expressão da COX-2 [35].

A apigenina (flavonóide) é um dos compostos relacionados ao efeito anti-inflamatório da Matricaria recutita. Além de diminuir a produção de TNF- $\alpha$ [36], também diminui a expressão da COX-2 [37]. $\alpha$-(-)-Bisabolol, outro constituinte da Matricaria recutita, reduz a produção de citocinas pró-inflamatórias e diminui a inflamação da pele [38] promovida por diversos agentes [39].

O mel de abelha é uma solução supersaturada composta principalmente de frutose e glucose, além de conter proteínas e aminoácidos, vitaminas, enzimas, minerais e outros componentes minoritários. O mecanismo de ação nas células da pele é condicionado à fonte botânica e inclui atividade antioxidante, indução da expressão de citocinas e metaloproteinases de matriz [15].

A redução do processo inflamatório em resposta ao uso do gel-creme, possivelmente está correlacionada ao efeito sinérgico promovido pela associação dos extratos glicólicos de Aloe Vera, Ginkgo biloba L., Panax ginseng, Matricaria recutita e do mel de abelha, visto que, cada componente possui um potencial efeito biológico.

\section{CONCLUSÃO}

Deste modo, podemos sugerir que a formulação elaborada nesse trabalho é um potencial agente anti-inflamatório tópico, podendo se tornar um alvo terapêutico contra a acne.

\section{AGRADECIMENTOS}

Agradecemos à FUNCAP e à Fundação Edson Queiroz pelo apoio financeiro e de infraestrutura. 


\section{REFERÊNCIAS BIBLIOGRÁFICAS}

1. Williams HC, Dellavalle RP, Garner S. Acne vulgaris. Lancet. 2012 Jan;379(9813):361-72, doi: 10.1016/S0140-6736(11)60321-8

2. Friedlander SF, Baldwin, HE, Mancini AJ, Yan AC, Eichenfield LF. The acne continuum: an age-based approach to therapy. Semin Cutan Med Surg. 2011 Sep;30(3):6-11, doi:10.1016/j.sder.2011.07.002

3. Weiss JS. Current options for the topical treatment of acne vulgaris. Pediatr Dermatol. 1997 Nov;14(6):480-88, doi: 10.1111/j.1525-1470.1997.tb00696.x

4. Webster GF. Topical tretinoin in topical therapy. J Am Acad Dermatol. 1998 Aug;39(2):38-44, doi: 10.1016/S0190-9622(98)70443-8

5. Thibout D. Acne. Semin Dermatol. 2002 47:109-17

6. Figueiredo A, Massa A, Picoto A, Soares AP, Bastos AS, Lopes C, Resende C, Rebelo C, Brandão FM, Pinto GM, Oliveira HS, Selores M, Gonçalo M, Bello RT. Avaliação e tratamento do doente com acne parte I: Epidemiologia, etiopatogenia, clínica, classificação, impacto psicossocial, mitos e realidades, diagnóstico diferencial e estudos complementares. Ver Portuguesa Clinica Geral. 2011 27:59-65

7. Draelos ZD. Procedimentos em Dermatologia Cosmética: Cosmecêutico. Editorial Santos. 2005. 228 p

8. Ruivo JSP. Fitocosmética: Aplicação de extratos vegetais em cosmética e dermatologia [Dissertação]. Porto (PT): Universidade Fernando Pessoa; 2012.

9. Alonso M, Támbara Y, López M, Aguilar CJ, Mayo O, Prieto E, Cremata J, Gerwig G, Kamerling H, Hardy E. On the isolation of immunostimulatory active acemannan from Aloe barbadensis. Biiotecnologia Aplicada. 2012 Jun;29(2):87-101

10. Cunha A. Farmacognosia e Fitoquímica. Fundação Calouste Gulbenkian 2010, 670 p.

11. Aburjai T, Natshef FM. Plants used in cosmetics. Phytotherapy Research. 2003 Nov;17(9):987-1000, doi: $10.1002 /$ ptr. 1363

12. Srivastava JK, Shanka E, Gupta S. Chamomile: A herbal medicine of the past with bright future. Mol. Med. Report. 2010 Nov;3(6):895-901, doi: 10.3892/mmr.2010.377

13. Chiu A, Kimball AB. Topical Review: topical vitamins, minerals, botanical ingredients as modulators of environmental and chronological skin damage. British Journal of Dermatolog. 2003 Oct;149(4):681-91, doi: $10.1046 / \mathrm{j} .1365-2133.2003 .05540 . \mathrm{x}$

14. Hexsel D, Orlandi C, Zechmeister do Prado, D. Botanical extracts used in the treatment of cellulite. Dermatologic Surgery. 2005 Jul;31(1):866-73, doi: 10.1111/j.1524-4725.2005.31733

15. Burlando B, Cornara L. Honey in dermatology and skin care: a review. Journal of Cosmetic Dermatology. 2013 Dec;12(4):306-13, doi: 10.1111/jocd.12058

16. Lee DS, Sinno S, Khachemoune A. Honey and Wound Healing: an Overview. American Journal of Clinical Dermatology. 2011 Jun;12(3):181-90, doi: 10.2165/11538930-000000000-00000

17.___. Ministério da Saúde, Agência Nacional de Vigilância Sanitária. Resolução RDC N No4, DE 30/Janeiro/2014. Disponível

em :http://portal.anvisa.gov.br/wps/wcm/connect/e321990042cf06e79b57dfafbc188c8f/Resolu\%C3\%A7\% $\mathrm{C} 3 \% \mathrm{~A} 3 \mathrm{o}+\mathrm{RDC}+\mathrm{n} \% \mathrm{C} 2 \% \mathrm{BA}+4+\mathrm{de}+30+\mathrm{de}+\mathrm{janeiro}+\mathrm{de}+204 . p d f$ ?MOD=AJPERES. Acesso em: 09 de maio de 2015.

18. _. Ministério da Saúde, Agência Nacional de Vigilância Sanitária. Resolução RDC N 3, DE 09 de Janeiro de 2012.2 Disponível em: http://portal.anvisa.gov.br/wps/wcm/connect/bb0e6e0049e93af4b7a5b76dcbd9c63c/RESOLU\%C3\%87 $\% \mathrm{C} 3 \% 83 \mathrm{ORDC}+\mathrm{N} \% \mathrm{C} 2 \% \mathrm{BA}+3+\mathrm{DE}+18+\mathrm{DE}+\mathrm{JANEIRO}+\mathrm{DE}+2012+-$ $+\mathrm{p} \%$ C3\%A1 gina+1+nova.pdf?MOD=AJPERES. Acesso em: 09 de maio de 2015.

19. . Ministério da Saúde, Agência Nacional de Vigilância Sanitária. Resolução RDC 29, 01 de Junho de 2012.2 Disponível em:http://bvsms.saude.gov.br/bvs/saudelegis/anvisa/2012/rdc0029_01_06_2012.html. Acesso em: 09 de maio de 2015.

20. Rasche WD. Formulação e análise de gel-crème hidratante facial. Lajeado (RS). Centro Universitário UNIVATES; 2014.

21. Brasil. Guia de Estabilidade de Produtos Cosméticos. Anvisa. Brasília: Anvisa, 2004. V.1, p.52 HTTP://www.anvisa.gov.br/divulga/public/series/cosmeticos.pdf. Acesso em: 25 de maio 2015

22. Friedrich M, Primo FT, Funck JAB, Laporta LV, Alves MP, Bittencourt CF, Escarrone ALV. Avaliação da estabilidade físico-química de crème não iônico inscrito no Formulário Nacional. Latin American Journal of Pharmacy. 2007 Abr;26(4):558-62

23. Stanley PL, Steiner S, Havens M, Tramposh KM. Mouse skin inflammation induced by multiple topical applications of 12-O-tetradecanoylphorbol-13-acetate. Skin Pharmacology. 1991 Jul;4(4):262-71, doi: $10.1159 / 000210960$ 
24. Yu RJ, Van Scott EJ. Alpha-hydroxyacids and carboxylic acids. J Cosmet. Dermatol. 2004 Apr;3(2):7687, doi: $10.1111 / j .1473-2130.2004 .00059 . x$

25. Chi YS, Lim H, Park H, Kim HP. Effects of wogonin, plant flavones from Scutellaria radix, on skin inflammation: in vivo regulation of inflammation-assiciated gene expression. Biochemical Pharmacology. 2003 Oct;66(7):1271-78, doi: 10.1016/S0006-2952(03)00463-5

26. Gupta M, Mazumder UK, Manikandan L, Bhattacharya S, Haldar PK, Roy S. Evaluation of antipyretic potential of Vernonia cinerea extract in rats. Phytotherapy Research. 2003 Aug;17(7):804-6, doi: $10.1002 /$ ptr. 1230

27. De Young LM, Kheifets JB, Ballaron SJ, Young JM. Edema and cell infiltration in the phorbol estertreated mouse ear aretemporally separate and can be differentially modulated by pharmacologic agents. Inflammation and Immunomodulation. 1989 Mar;26(3):335-41

28. Davis RH, Leitner MG, Russo JM. Topical anti-inflammatory activity of Aloe vera as measured by ear swelling. J Am Podiatr Med Assoc. 1987 Nov;77(11):610-2, doi: 10.7547/87507315-77-11-610

29. Coats BC, Ahola R. The silent healer, a modern study of Aloe vera. Bill C Coats, Garland, TX, 1979

30. Finberg MJ, Muntingh GL, van Rensburg CE. A comparison of the leaf gel extracts of Aloe ferox and Aloe vera in the topical treatment of atopic dermatitis in Balb/c mice. Inflammopharmacology. 2015 Dec;23(6):337-41, doi: 10.1007/s10787-015-0251-2

31. Lim H, Son KH, Chang HW, Kang SS, Kim HP. Effects of anti-inflammatory biflavonoid, ginkgetin, on chronic skin inflammation. Biol Pharm Bull. 2006 May;29(5):1046-9

32. Fei R, Fei Y, Zheng S, Gao YG, Sun HX, Zeng XL. Purified polysaccharide from Ginkgo biloba leaves inhibits P-selectin-mediated leucocyte adhesion and inflammation. Acta Pharmacol Sin. 2008 Apr;29(4):499-506, doi: 10.1111/j.1745-7254.2008.00765.x

33. Park SH, Seo W, Eun H, Kim SY, Jo E, Kim MH, Choi WM, Lee JH, Shim YR, Cui CH, Kim SC, Hwang CY, Jeong WI. Protective effects of ginsenoside F2 on 12-O-tetradecanoylphorbol-13-acetateinduced skin inflammation in mice. Biochem Biophys Res Commun. 2016 Sep 30;478(4):1713-9, doi: 10.1016/j.bbrc.2016.09.009

34. Paul S, Shin HS, Kang SC. Inhibition of inflammations and macrophage activation by ginsenoside-Re isolated from Korean ginseng (Panax ginseng C.A. Meyer). Food Chem Toxicol. 2012 May;50(5):135461, doi: $10.1016 /$ j.fct.2012.02.035

35. Lee JY, Shin JW, Chun KS, Park KK, Chung WY, Bang YJ, Sung JH, Surh YJ. Antitumor promotional effects of a novel intestinal bacterial metabolite (IH-901) derived from the protopanaxadiol-type ginsenosides in mouse skin. Carcinogenesis. 2005 Feb;26(2):359-67, doi: 10.1093/carcin/bgh313

36. Miguel FG, Cavalheiro AH, Spinola NF, Ribeiro DL, Barcelos GR, Antunes LM, Hori JI, MarqueleOliveira F, Rocha BA, Berretta AA. Validation of a RP-HPLC-DAD Method for Chamomile (Matricaria recutita) Preparations and Assessment of the Marker, Apigenin-7-glucoside, Safety and AntiInflammatory Effect.Evid Based Complement Alternat Med. 2015;2015:828437, doi: $10.1155 / 2015 / 828437$

37. Byun S, Park J, Lee E, Lim S, Yu JG, Lee SJ, Chen H, Dong Z, Lee KW, Lee HJ. Src kinase is a direct target of apigenin against UVB-induced skin inflammation.Carcinogenesis. 2013 Feb;34(2):397-405, doi: $10.1093 /$ carcin/bgs358

38. Maurya AK, Singh M, Dubey V, Srivastava S, Luqman S, Bawankule DU. $\alpha$-(-)-bisabolol reduces proinflammatory cytokine production and ameliorates skin inflammation. Curr Pharm Biotechnol. 2014;15(2):173-81

39. Leite G de O, Leite LH, Sampaio Rde S, Araruna MK, de Menezes IR, da Costa JG, Campos AR. (-)- $\alpha-$ Bisabolol attenuates visceral nociception and inflammation in mice. Fitoterapia. 2011 Mar;82(2):20811, doi: $10.1016 /$ j.fitote.2010.09.012 